\title{
Sevoflurane-Induced Down-regulation of Hippocampal Oxytocin and Arginine Vasopressin Impairs Juvenile Social Behavioral Abilities
}

\author{
Zhi-Bin Zhou • Xiao-Yu Yang • Bao-Long Yuan • \\ Li-Jun Niu • Xue Zhou • Wen-Qi Huang • Xia Feng • \\ Li-Hua Zhou
}

Received: 26 October 2014 / Accepted: 13 November 2014 / Published online: 25 November 2014

(C) The Author(s) 2014. This article is published with open access at Springerlink.com

\begin{abstract}
Cumulative evidence indicates that early childhood anesthesia can alter a child's future behavioral performance. Animal researchers have found that sevoflurane, the most commonly used anesthetic for children, can produce damage in the neonatal brains of rodents. To further investigate this phenomenon, we focused on the influence of sevoflurane anesthesia on the development of juvenile social behavioral abilities and the pro-social proteins oxytocin (OT) and arginine vasopressin (AVP) in the neonatal hippocampus. A single 6-h sevoflurane exposure for postnatal day 5 mice resulted in decreased OT and AVP messenger RNA (mRNA) and protein levels in the hippocampus. OT and AVP proteins became sparsely distributed in the dorsal hippocampus after the exposure to sevoflurane. Compared with the air-treated group,
\end{abstract}

Z.-B. Zhou $\cdot$ X.-Y. Yang $\cdot$ B.-L. Yuan · L.-J. Niu $\cdot$ X. Zhou $\cdot$

W.-Q. Huang $\cdot X$. Feng $(\triangle)$

Department of Anesthesiology, The First Affiliated Hospital of Sun Yat-Sen University, No. 58 Zhongshan 2nd Road, Guangzhou, China e-mail: fengxia@mail.sysu.edu.cn

Z.-B. Zhou

e-mail: zhouzhibin1986@aliyun.com

X.-Y. Yang

e-mail: wooyoung@163.com

B.-L. Yuan

e-mail: yuanb16523@163.com

L.-J. Niu

e-mail: 183513575@qq.com

X. Zhou

e-mail: 550145912@qq.com

W.-Q. Huang

e-mail: huangwenqisysu@163.com

\section{L.-H. Zhou}

Department of Anatomy, Zhong Shan Medical College, Sun Yat-sen University, No. 74 Zhongshan 2nd Road, Guangzhou, China

e-mail: zhoulih@mail.sysu.edu.cn mice in the sevoflurane-treated group showed signs of impairment in social recognition memory formation and social discrimination ability. Sevoflurane anesthesia reduces OT and AVP activities in the neonatal hippocampus and impairs social recognition memory formation and social discrimination ability in juvenile mice.

Keywords Sevoflurane - Oxytocin · Arginine vasopressin · Hippocampus $\cdot$ Social behavior

$\begin{array}{ll}\text { Abbreviations } \\ \text { OT } & \text { Oxytocin } \\ \text { AVP } & \text { Arginine vasopressin } \\ \text { IEI } & \text { Inter-encounter interval } \\ \text { PCR } & \text { Polymerase chain reaction } \\ \text { qPCR } & \text { Quantitative polymerase chain reaction } \\ \text { GAPDH } & \text { Glyceraldehyde phosphate dehydrogenase } \\ \text { RNA } & \text { Ribonucleic acid } \\ \text { mRNA } & \text { Messenger ribonucleic acid } \\ \text { PMSF } & \text { Phenylmethylsulfonyl fluoride } \\ \text { SDS } & \text { Sodium dodecyl sulfate } \\ \text { TEMED } & \text { Tetramethylethylenediamine } \\ \text { PB } & \text { Phosphate buffer } \\ \text { EDTA } & \text { Ethylenediamine tetraacetic acid }\end{array}$

Introduction

According to retrospective clinical data, children who receive general anesthesia under the age of 2 have twice the incidence of developing autistic symptoms that cause learning disabilities, such as hyperactivity and attention deficit, at a later age (Sprung et al. 2012; Wilder et al. 2009). In animal studies, extensive neural apoptosis was found in neonatal mouse brains after 6 h of $3 \%$ sevoflurane anesthesia. Compromised 
responses to stress conditions and abnormal social behavioral changes resembling autism were subsequently observed when these mice reached adulthood (Satomoto et al. 2009). Previous research showed that neonatal exposure to $2.3 \%$ sevoflurane for $6 \mathrm{~h}$ resulted in the retardation of the sensorimotor reflex development of rats, but the spatial navigation ability of the rats was intact (Feng et al. 2012). Given that sevoflurane exerts multifactorial neurobehavioral impacts, social memory development could possibly be affected as well.

In a genomic microarray analysis conducted by Pan et al. (2011), among the 28,000 Rattus genes investigated, oxytocin (OT) and arginine vasopressin (AVP) were found to be significantly down-regulated after sevoflurane exposure. Known as neurohypophysial hormones, OT and AVP are also important neurotransmitters that are closely related to social memory development. Ample studies have confirmed that oxytocinergic and vasopressinergic fibers and their associated receptors exist in the mammalian hippocampus (Feldman et al. 1997; Knobloch et al. 2012; Stoop 2012) and build up the learning and memory functions in social behavioral formation (Bielsky et al. 2004; Stoop 2012). Therefore, we speculate that sevoflurane may affect social memory development in juvenile mammals by regulating OT and AVP expression in the hippocampus.

To investigate this hypothesis, we exposed neonatal mice to sevoflurane and assessed the transcriptional and translational changes of OT and AVP after anesthesia. Social recognition and discrimination abilities were examined to determine whether a single early exposure of sevoflurane could have long-term deleterious effects on juvenile social behavioral development.

\section{Methods}

Animals

This study was approved by the Institutional Animal Care and Use Committee at Sun Yat-Sen University (Guangzhou, Guangdong, China). Animals were obtained from the Experimental Animal Center of Sun Yat-Sen University. To minimize the number of animals used and their suffering, 48 C57BL male mice (from eight litters) were used. They were kept in a 12-h light-dark cycle environment at $25^{\circ} \mathrm{C}$ with access to water and food ad libitum.

\section{Sevoflurane Exposure}

Mice at postnatal day 5 (PN5d; 3-5 g) were randomly allocated into the air-treated (control; $n=24$ ) and sevofluranetreated (sevo; $n=24$ ) groups. Mice in the sevo group were placed in a transparent plastic container filled with $2.3 \%$ sevoflurane. Sevoflurane was continuously supplied by a vaporizer with a fresh airflow of $2 \mathrm{~L} \mathrm{~min}^{-1}$. The concentrations of sevoflurane, oxygen and carbon dioxide were monitored by a gas analyzer (Detex-Ohmeda, Louisville, KY, USA) in real time. The temperature in the box was controlled at $38^{\circ} \mathrm{C}$ using an infrared heater (NPS-A3 heater, Midea Co., Guangdong, China). After $6 \mathrm{~h}$ of sevoflurane exposure, mice were again exposed to air and then placed back into their maternal cages. Mice of control group were exposed to air in the same apparatus for $6 \mathrm{~h}$.

\section{Social Behavioral Tests}

At postnatal day 20, the mice were already capable of social interaction but had not yet reached puberty (the sexual maturation time for $\mathrm{C} 57 \mathrm{BL}$ mice is estimated to be 5-8 weeks postnatally) (Pinter et al. 2007). Behavioral tests were employed to examine their social recognition and discrimination abilities (Winslow 2003). All mice used in this experiment were aged postnatal day 20 (including the female stimulus mice), and six mice were allocated into each group.

\section{Recognition Trial}

The test cage $(20 \times 20 \times 20 \mathrm{~cm})$ was located in a fixed position in a quiet, moderately lighted room. Before the trial, the subject mouse was placed into the test cage for a habituation period of $30 \mathrm{~min}$. Then, a stimulus mouse was introduced into the test cage for a 5-min familiarization period (session 1). The stimulus mouse was positioned along the wall furthest from the test subject. After $5 \mathrm{~min}$, the stimulus mouse was removed from the test cage. The mice were separated for a 30-min interencounter interval (IEI), and then the same stimulus mouse was again introduced into the test cage for another $5 \mathrm{~min}$ familiarization period (session 2). The prior process was repeated until each subject mouse had encountered its corresponding stimulus mouse four times (as depicted in Fig. 1).

During each familiarization period, the amount of time the subject mouse spent investigating the stimulus mouse was recorded. The investigation time was counted as any time when the subject mouse used its nose to inspect any portion of body of the stimulus mouse within $2 \mathrm{~cm}$.

\section{Discrimination Trial}

The last familiarization (session 4) was followed by an extended IEI of $90 \mathrm{~min}$. After this extended IEI, the same stimulus mouse and a novel stimulus mouse were introduced simultaneously into the test cage for a 5-min discrimination period.

During the discrimination period, the amount of time the subject spent investigating the same stimulus mouse and the novel stimulus mouse were recorded, respectively. The investigation criteria were the same as in recognition trial. 
A

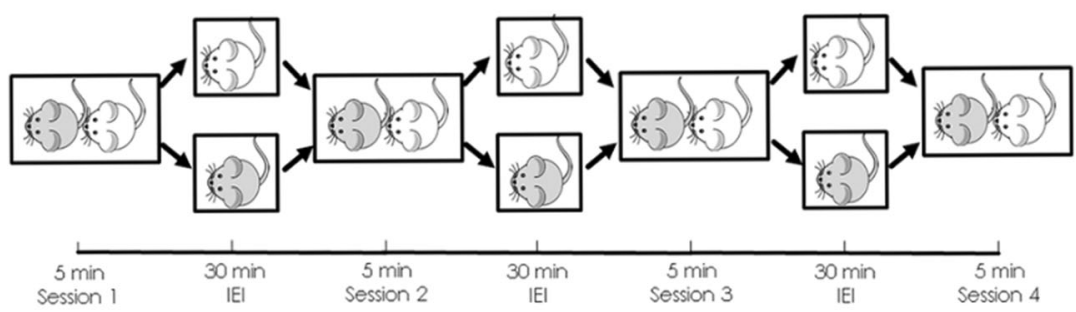

C

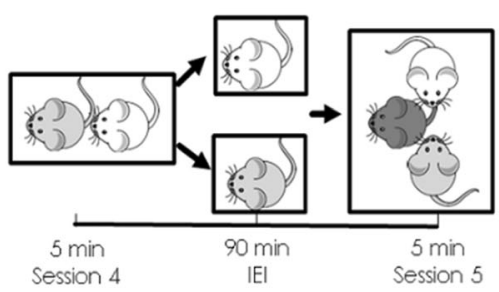

B

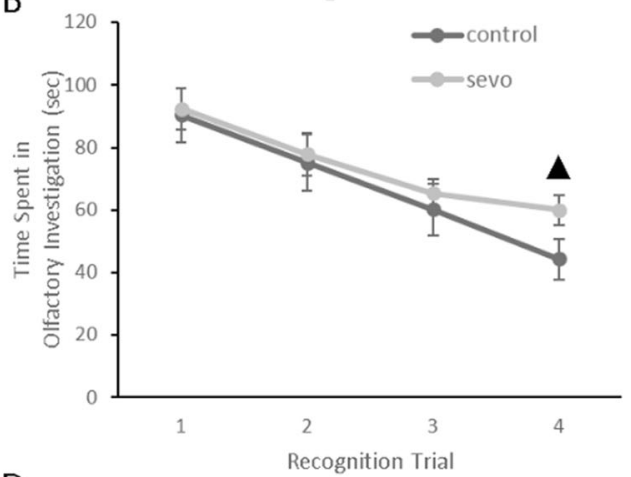

D

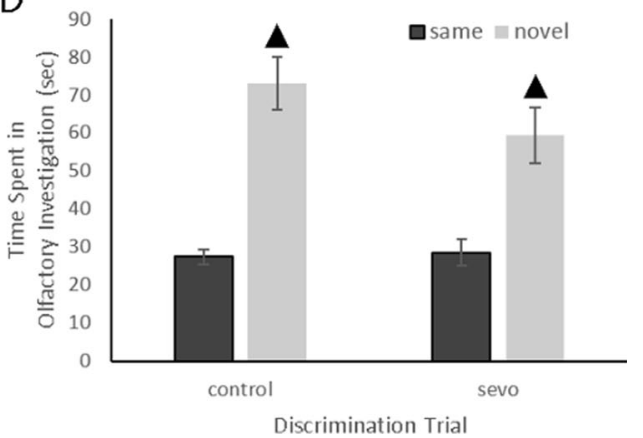

Fig. 1 Illustration of the social recognition and social discrimination trials and raw results data. a Illustration of the social recognition paradigm. b Raw data of the olfactory investigation times in each session of the social recognition trial $\left({ }^{\mathbf{\Delta}} P<0.001\right.$ compared between groups). $\mathbf{c}$ Illustration of the social discrimination paradigm. $\mathbf{d}$ Raw data

Raw data from both social recognition and social discrimination trials were presented as the Ratio of Investigation Duration (RID) in Table 2. RIDr (recognition) represents the establishment of social memory formation. RIDr equals the amount of time the subject spent investigating the same stimulus mouse in the present session divided by that of the previous session. The lower the RIDr value, the more developed the subject's social memory formation. RIDd (discrimination) represents the social discrimination ability. RIDd equals the amount of time the subject spent investigating the same stimulus mouse divided by that spent investigating the novel stimulus mouse in the discrimination period. The lower the RIDd value, the stronger the subject's social discrimination ability.

\section{Real-Time Quantitative PCR for OT and AVP mRNA Levels}

Four hours after sevoflurane exposure, mice of the control $(n=$ $6)$, and sevo $(n=6)$ groups were deeply anesthetized with $10 \%$ chloral hydrate $(360 \mathrm{mg} / \mathrm{kg}$, i.p. $)$. Bilateral hippocampal tissue was dissected out on ice and then transferred to EP tubes that were precooled with liquid nitrogen. Total RNA was extracted using RNAiso Plus (Takara, Japan) and stored at $-80{ }^{\circ} \mathrm{C}$ for later use. The concentration and purity of RNA were measured under a microvolume UV spectrophotometer (NanoDrop 2000, Thermo Fisher Scientific, USA). According of the olfactory investigation times in session 5 of the social discrimination trial $\left({ }^{\mathbf{\Delta}} P<0.001\right.$ compared between the time spent investigating the same stimulus mouse and that of the novel stimulus mouse). All results are presented as the mean $\pm \mathrm{SD}$

to the measured concentrations, all samples were diluted with RNase-free water to $1 \mu \mathrm{g} / \mu \mathrm{l}$ for reverse transcription. According to the instructions of the M-MLV reverse transcriptase reaction kit (Invitrogen, USA), a 20- $\mu$ l reaction volume was prepared for $1 \mu \mathrm{g}$ total RNA. According to the instructions of the SYBR Green quantitative polymerase chain reaction (qPCR reaction kit; Invitrogen, USA), a $25-\mu 1$ reaction volume was prepared for qPCR. The primer sequences used for qPCR are listed in Table 1.

\section{Western Blot Analysis for OT and AVP Protein Levels}

Four hours after sevoflurane exposure, bilateral hippocampal tissue was dissected out as described above (control group, $n=$ 6; sevo group, $n=6$ ) and immediately homogenized with $100 \mathrm{mg} / \mathrm{ml}$ RIPA Lysis Buffer (Shenergy Biocolor Co., China) and $1 \%(v / v)$ PMSF (Shenergy Biocolor Co., China). After $20 \mathrm{~min}$ of centrifugation at $13,000 \times \mathrm{g}$ at $4{ }^{\circ} \mathrm{C}$, the supernatant was aspirated and stored at $-80{ }^{\circ} \mathrm{C}$ for further use. The extracted hippocampal proteins were electrophoresed using a $5 \%$ stacking gel at $80 \mathrm{~V}$ for $20 \mathrm{~min}$ and $12 \%$ separating gel at $120 \mathrm{~V}$ for $40 \mathrm{~min}$ and were then transferred onto polyvinylidene fluoride membranes (Pall Co., USA). The blots were immunoreacted with anti-OT (1:500, AB2078, Abcam, UK), anti-AVP (1:500, AB48322, Abcam, UK), and anti-GAPDH (1:1000, SC25778, Santa Cruz, USA) 
Table 1 Calculated RID results in the social recognition and discrimination trials of juvenile mice

\begin{tabular}{|c|c|c|c|c|c|}
\hline & \multirow[t]{2}{*}{ IEI (min) } & \multicolumn{2}{|l|}{ RIDr } & \multicolumn{2}{|l|}{ RIDd } \\
\hline & & Control $(n=6)$ & Sevo $(n=6)$ & Control $(n=6)$ & Sevo $(n=6)$ \\
\hline \multirow[t]{4}{*}{ Social recognition paradigm } & $30($ session 1$)$ & - & - & - & - \\
\hline & $30($ session 2$)$ & $0.83 \pm 0.06$ & $0.84 \pm 0.03$ & - & - \\
\hline & $30($ session 3$)$ & $0.80 \pm 0.08$ & $0.84 \pm 0.05$ & - & - \\
\hline & $30($ session 4$)$ & $0.74 \pm 0.06$ & $0.91 \pm 0.05^{\mathbf{\Delta}}$ & - & - \\
\hline Social discrimination paradigm & $90($ session 5$)$ & - & - & $0.37 \pm 0.04$ & $0.49 \pm 0.07^{\star}$ \\
\hline
\end{tabular}

All results are presented as the mean $\pm \mathrm{SD}$

$R I D r$ recognition ratio of investigation duration, $R I D d$ discrimination ratio of investigation duration

$\triangle P<0.001$ compared between groups)

antibodies. The ECL-PLUS Reagents Kit (Com Win Biotech Co., Ltd, China) was utilized to detect the bands. The results were examined under a digital imaging system (ImageQuant Las4000 mini, General Electric, USA). The optical density (OD) was then analyzed with Image J software.

Immunohistochemical Analysis for OT and AVP Distribution

Four hours after sevoflurane exposure, mice of the control $(n=$ $6)$ and sevo $(n=6)$ groups were executed as described above and transcardially perfused with normal saline until the liver and lung appeared translucent. The mice were continuously perfused with $4 \%$ paraformaldehyde in $0.1 \mathrm{M} \mathrm{PB}\left(\mathrm{NaH}_{2} \mathrm{PO}_{4}\right.$. $2 \mathrm{H}_{2} \mathrm{O}, 2.96 \mathrm{~g} ; \mathrm{Na} 2 \mathrm{HPO}_{4} \cdot 12 \mathrm{H}_{2} \mathrm{O}, 29 \mathrm{~g}$ dissolved in 11 water) for 10-20 $\mathrm{min}$. The brains were then removed for paraformaldehyde fixation overnight. After dehydration and paraffin embedding, coronal hippocampal sections ( $5 \mu \mathrm{m}$ thick) were sliced, deparaffinized, and hydrated. Antigen retrieval was performed with EDTA solution (Beyotime, China). Sections were incubated with anti-OT (1:100; AB2078, Abcam, UK) and anti-AVP (1:100; AB68669, Abcam, UK) antibodies. The final results were examined under a microscope imaging system (DM 2500B, Leica, Germany). Image-Pro Plus Software was utilized to count the number of positive particles in the area of dorsal hippocampal region.

\section{Statistical Analysis}

GAPDH was used as the internal control. The Livak Method $\left(2^{-\triangle \Delta \mathrm{Ct}}\right.$ method) was employed for qPCR data analysis. Briefly, an $A$ value was calculated in each sample ( $A=\mathrm{Ct}$ of the target gene $-\mathrm{Ct}$ of GAPDH), then $2^{-n}$ was calculated to represent the fold change of gene expression in the sevo group compared with the control group ( $n=A$ value of sevo group $-A$ value of control group). For western blot analysis, the ratio of the optical densities (OD of the target protein divided by that of GAPDH) was calculated to represent the target protein level. All data were described as the mean \pm standard deviation. IBM SPSS Statistics 20 software was used for statistical analysis. Comparisons of the mean values between groups were performed using independent sample $t$ tests. $P$ values of $\leq 0.05$ were considered statistically significant.

\section{Results}

\section{Social Behavioral Tests}

The results of the social recognition trial indicated that after several familiarization periods, social recognition memory was formed in both control and sevo mice, as could be seen from the decline in the olfactory investigation time. However, compared with the air-treated mice in session 4 , mice in the sevoflurane-treated group still maintained a relatively high investigative interest, with a high RIDr value (Fig. 1; Table 2), suggesting that the formation of social memory in the sevoflurane-treated mice is not as well established as that in the controls.

In the subsequent social discrimination trial, sevofluranetreated mice had a higher RIDd value, suggesting a compromised social discrimination ability after neonatal sevoflurane exposure.

Table 2 Forward and reverse primers used for quantitative PCR

\begin{tabular}{lll}
\hline Gene symbol & Orientation & Primer sequence $\left(5^{\prime} \rightarrow 3^{\prime}\right)$ \\
\hline OT & Forward & CCTACAGCGGATCTCAGACTGA \\
& Reverse & TCAGAGCCAGTAAGCCAAGCA \\
AVP & Forward & TCGCCAGGATGCTCAACAC \\
& Reverse & TCCGAAGCAGCGTCTTGG \\
GAPDH & Forward & CCATCACCATCTTCCAGGAGCGAG \\
& Reverse & GATGGCATGGACTGTGGTCATGAG
\end{tabular}

$O T$ oxytocin, $A V P$ arginine vasopressin, $G A P D H$ glyceraldehyde-3phosphate dehydrogenase 


\section{Real-Time Quantitative PCR for OT and AVP mRNA}

The results of qPCR showed the down-regulation of OT and AVP messenger RNA (mRNA) levels in the mouse hippocampus $4 \mathrm{~h}$ after sevoflurane exposure (Fig. 2).

\section{Western Blot Analysis for OT and AVP Protein Levels}

Four hours after sevoflurane exposure, OT and AVP protein levels were decreased in the mouse hippocampus (Fig. 3).

Immunohistochemical Analysis for OT and AVP Distribution

The results of immunohistochemical staining showed that OTand AVP-positive particles were mainly located near the dentate gyrus and the inner part of the CA1 region in the dorsal hippocampus. Four hours after sevoflurane exposure, both OT- and AVP-positive particles decreased and became sparsely distributed (Fig. 4).

\section{Discussion}

In previous studies, after sevoflurane exposure, abnormal morphological changes of hippocampal neurons were observed, accompanied by an upregulation of the cell apoptosis marker activated caspase- 3 protein. Activated caspase- 3 protein reached its peak level at 4-6 h after the exposure (Feng et al. 2012). As a result, we assumed that $4 \mathrm{~h}$ after exposure was the time when most hippocampal neurons had undergone vast damage and were at their most vulnerable state. Thus, changes in the OT and AVP levels, if any, could likely be observed at this time point.

One study showed that intracerebral administration of oxytocin receptor agonists reduced the activation of caspase-3 caused by sevoflurane, which indicated a potential neuroprotective role of oxytocin (Cao et al. 2012). As a result, the down-regulation of oxytocin after sevoflurane exposure could imply a compromised protective mechanism that predisposes hippocampal neurons to noxious influences.

Social interaction in rodents is roughly achieved by olfactory investigation. Although social behaviors are varied, most of those behaviors involving social interaction are based on social recognition and discrimination abilities. These abilities are by and large subject to OT and AVP regulation in the hippocampus (Bielsky et al. 2004; Choleris et al. 2009; Dantzer et al. 1987; Ferguson et al. 2002; Winslow and Insel 2004).

Pharmacological studies in the past confirmed that AVP can enhance social recognition memory (Boccia et al. 1998; Caldwell et al. 2008). In AVP-receptor (AVPR) knockout mice, social memory deficits and abnormal emotional changes were observed (Bielsky et al. 2004). Brattleboro rats carrying a spontaneous null mutation of the AVP gene showed innate impairment in social recognition memory, similar to that of AVPR knockout mice. Moreover, AVP administration into the CNS restored their social memory (Engelmann and Landgraf 1994). OT, which is equally important as AVP, serves a similar function in the CNS to facilitate social recognition memory (Bielsky et al. 2004; Ferguson et al. 2001; Ross and Young 2009). In mice lacking the OT gene, social amnesia was observed (Ferguson et al. 2000; Lee et al. 2009). In humans, nasal administration of OT significantly improved the ability to understand people's feelings from facial clues (Domes et al. 2007; Guastella et al. 2010), increased the duration of eye contact (Guastella et al. 2008a, b), and elevated the ratings of people's facial trustworthiness and attractiveness ( $\mathrm{Di}$ Simplicio et al. 2009; Guastella et al. 2008a, b; Theodoridou et al. 2009). Modahl et al. reported that plasma OT levels in children with social behavioral disorders were lower than those of age-matched controls (Modahl et al. 1998); these lower levels of OT might be due to the impaired processing of OT precursor (Green et al. 2001).

Recent studies have suggested social behavioral disorders may involve epigenetic modifications (Miyake et al. 2012;
Fig. 2 qPCR results for OT and AVP. a Hippocampal OT gene transcription levels $\left({ }^{\mathbf{\Delta}} P<0.001\right.$ compared between groups). b Hippocampal AVP gene transcription levels $\left({ }^{\mathbf{\Lambda}} P<0.001\right.$ compared between groups)
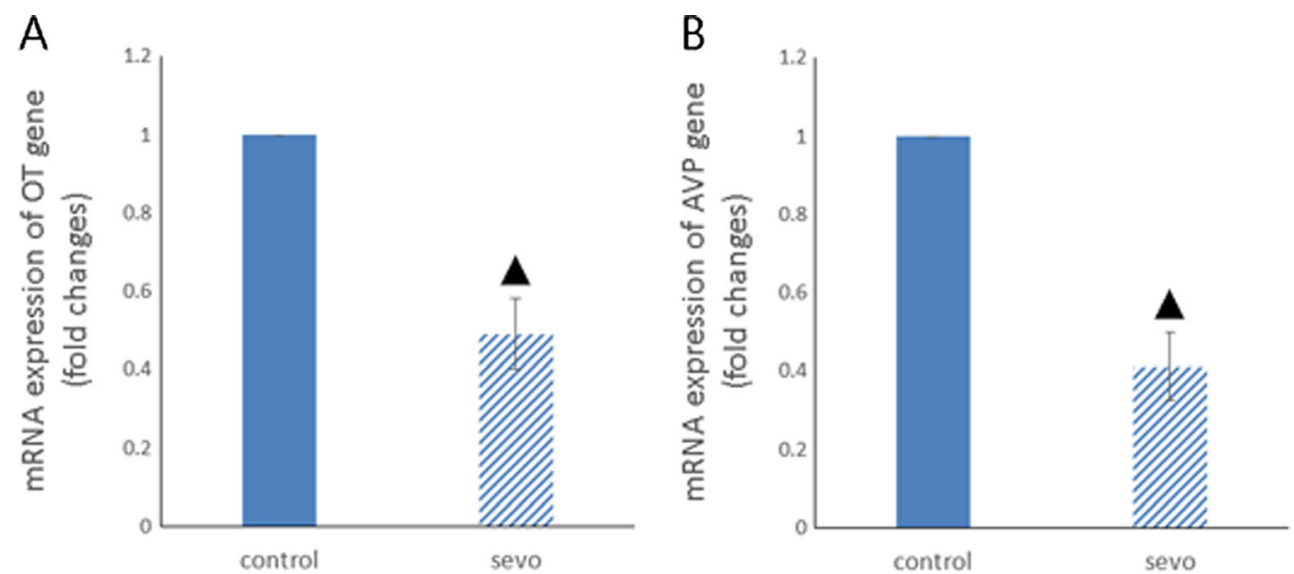
Fig. 3 Western blot results for OT and AVP. a Western blot results for OT. b Western blot results for AVP. c Hippocampal OT protein levels $\left({ }^{\mathbf{A}} P<0.01\right.$ compared between groups). d Hippocampal AVP protein levels $\left({ }^{\wedge} P<0.01\right.$ compared between groups)
A

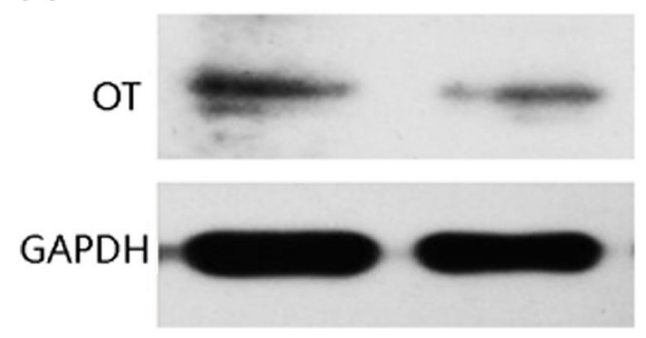

C

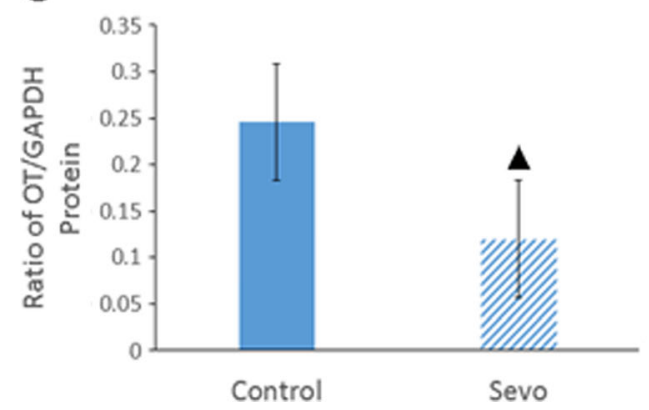

B

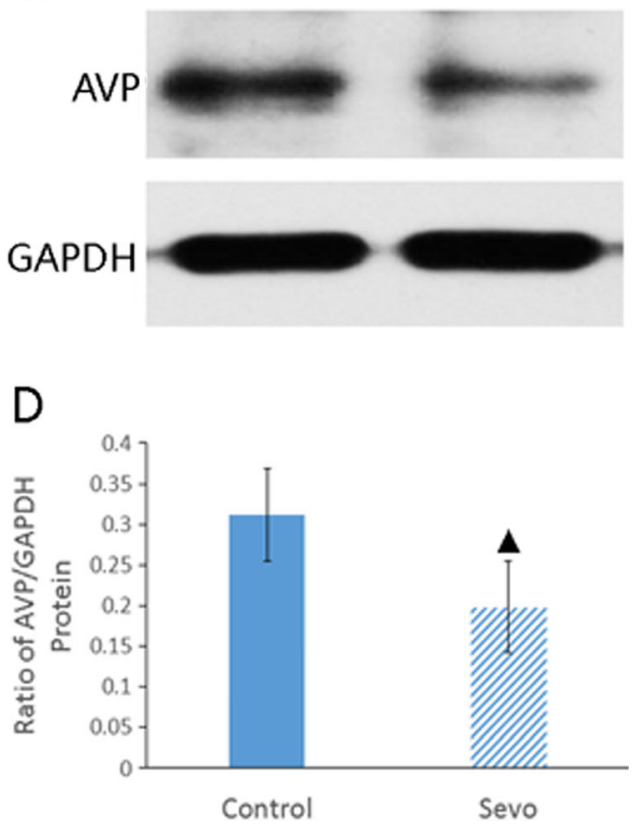

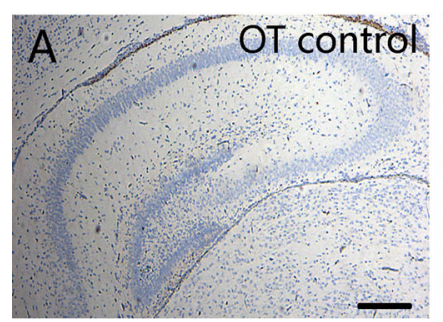
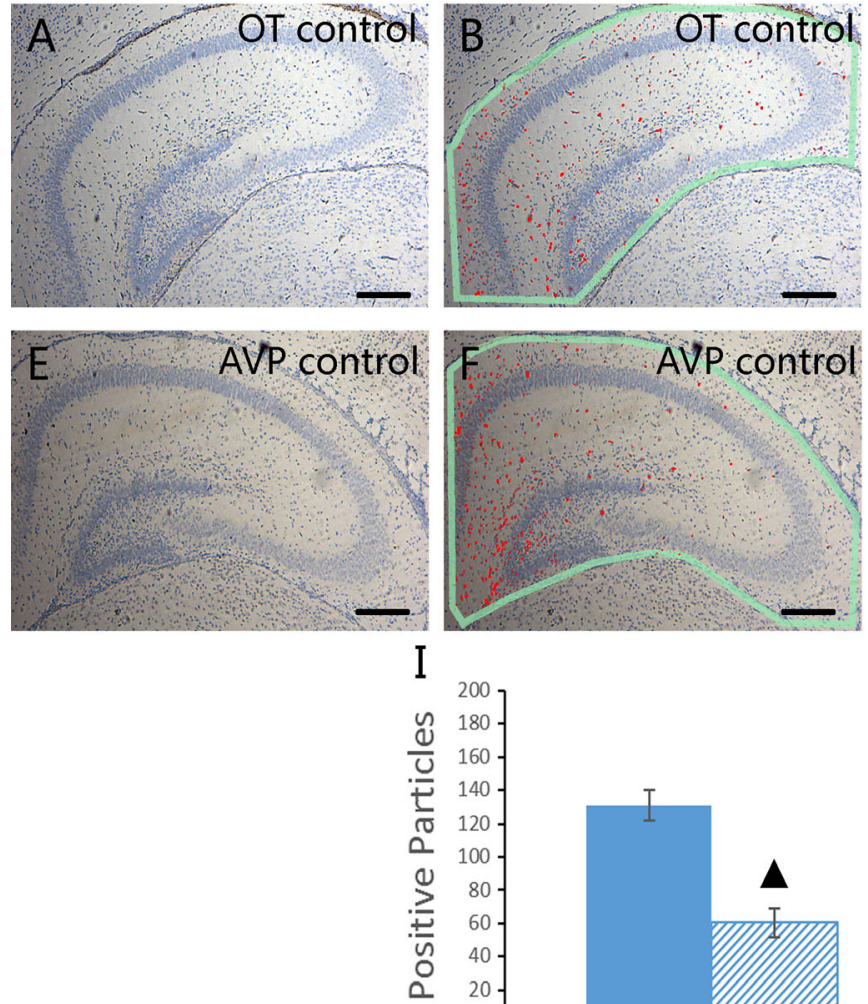

$\frac{1}{\frac{1}{0}}$

$\left.\begin{array}{r}200 \\ 180 \\ 160 \\ 140 \\ 120 \\ 100 \\ 80 \\ 60 \\ 40 \\ 20 \\ 0\end{array}\right]$

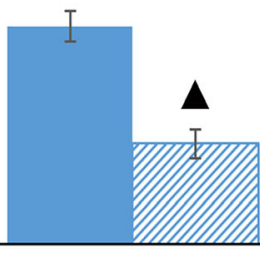

OT

Fig. 4 Immunohistochemical staining of OT and AVP in the dorsal hippocampus. a, b OT immunohistochemical staining results and the corresponding marking illustrations of positive particles in the airtreated group. c, d OT immunohistochemical staining results and the corresponding marking illustrations of positive particles in the sevoflurane-treated group. e, f AVP immunohistochemical staining
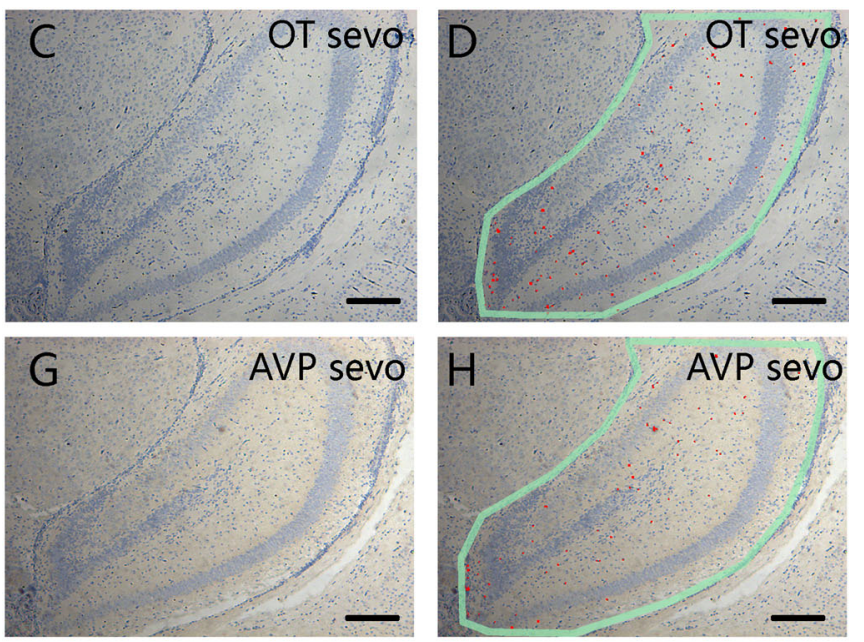

- control

$(n=6)$

sevo

$(n=6)$ 
Schanen 2006), including methylation of certain genes (Jones et al. 2008). In 2009, Gregory et al. (2009) used genome-wide arrays to identify gene variants in 119 patients from families with a history of autism. A deletional mutation in the OT receptor (OTR) gene was discovered in one patient, who had one affected sibling with hypermethylation in the promoter of the OTR gene (Gregory et al. 2009). Hence, it can be inferred that hypermethylation of the OTR gene promoter leads to its low expression. To further examine this, researchers investigated DNA methylation at this region in 20 autistic patients and 20 controls. Their results revealed that patients with social behavior disorders had significantly higher methylation statuses at all three $\mathrm{CpG}$ sites of the OTR gene promoter (Gregory et al. 2009). Thus, it is now worth considering whether sevoflurane administration induces the methylation of the OT and AVP gene promoters to down-regulate their transcription.

The above evidence indicates that it is highly possible that the observed impairments of juvenile social recognition and discrimination abilities are closely related to the altered hippocampal OT and AVP expression after early sevoflurane exposure.

Studies in rodents have confirmed that during normal postnatal development, OT mRNA production may rise in the brain by many fold until puberty, with equal levels in both sexes; no major discrepancy was found between age-matched male and female mice during this period (Burbach et al. 1992; Chitme and Hiremath 2009). Protein concentrations and distributions of OT and OTR in the CNS are also of the same levels before puberty, as examined in both male and female rodents (Burbach et al. 1992; Lee et al. 2009; Pedersen et al. 1992). However, during estrus cycles, pregnancy, parturition, and lactation, considerable fluctuations of OT levels occur in female adults (Burbach et al. 1992; Gimpl and Fahrenholz 2001). Therefore, most behavioral studies in adult rodents only investigate male subjects.

A previous study revealed that in adult mice, neonatal exposure to sevoflurane impaired social memory (Satomoto et al. 2009). However, no study has ever investigated the effects of sevoflurane on the impairment on juvenile social behavioral abilities, especially on recognition and discrimination abilities, even though these basic properties are critical for the development of other social behaviors at later ages. However, from the research results so far, it is evident that sevoflurane down-regulates the activities of OT and AVP in the brain; these changes are accompanied by impaired juvenile social recognition and discrimination abilities.

Acknowledgments This work was supported by Funding from Guangdong Science and Technology Planning Project (No. 2011B050400024) and Guangzhou International Science and
Technology Cooperation Project (No. 2012J5100019). The sources of funding had no role in the design and conduct of this project or in the preparation of the manuscript.

Open Access This article is distributed under the terms of the Creative Commons Attribution License which permits any use, distribution, and reproduction in any medium, provided the original author(s) and the source are credited.

\section{References}

Bielsky IF, Hu SB, Szegda KL, Westphal H, Young LJ (2004) Profound impairment in social recognition and reduction in anxiety-like behavior in vasopres $\mathrm{s}$ in $\mathrm{V} 1 \mathrm{a}$ receptor knockout mice. Neuropsychopharmacology 29(3):483-493

Boccia MM, Kopf SR, Baratti CM (1998) Effects of a single administration of oxytocin or vasopressin and their interactions with two selective receptor antagonists on memory storage in mice. Neurobiol Learn Mem 69(2):136-146

Burbach JPH, Adan RA, Bree FM (1992) Regulation of oxytocin gene expression and forms of oxytocin in the brain. Ann N Y Acad Sci 652(1):1-13

Caldwell HK, Lee HJ, Macbeth AH, Young WS 3rd (2008) Vasopressin: behavioral roles of an "original" neuropeptide. Prog Neurobiol 84(1):1-24

Cao W, Pavlinec C, Gravenstein N, Seubert CN, Martynyuk AE (2012) Roles of aldosterone and oxytocin in abnormalities caused by sevoflurane anesthesia in neonatal rats. Anesthesiology 117(4): $791-800$

Chitme H, Hiremath G (2009) Possible central role of oxytocin in neurobehaviour of male rats and mice. Adv Med Dental Sci 3(1):21-28

Choleris E, Clipperton-Allen AE, Phan A, Kavaliers M (2009) Neuroendocrinology of social information processing in rats and mice. Front Neuroendocrinol 30(4):442-459

Dantzer R, Bluthe RM, Koob GF, Le Moal M (1987) Modulation of social memory in male rats by neurohypophyseal peptides. Psychopharmacol (Berl) 91(3):363-368

Di Simplicio M, Massey-Chase R, Cowen PJ, Harmer CJ (2009) Oxytocin enhances processing of positive versus negative emotional information in healthy male volunteers. J Psychopharmacol 23(3): $241-248$

Domes G, Heinrichs M, Michel A, Berger C, Herpertz SC (2007) Oxytocin improves "mind-reading" in humans. Biol Psychiatry 61(6):731-733

Engelmann M, Landgraf R (1994) Microdialysis administration of vasopressin into the septum improves social recognition in Brattleboro rats. Physiol Behav 55(1):145-149

Feldman RS, Meyer JS, Quenzer LF (1997) Principles of neuropsychopharmacology. Sinauer Associates, Sunderland, Mass

Feng X, Liu JJ, Zhou X, Song FH, Yang XY, Chen XS, Huang WQ et al (2012) Single sevoflurane exposure decreases neuronal nitric oxide synthase levels in the hippocampus of developing rats. Br J Anaesth 109(2):225-233

Ferguson JN, Young LJ, Hearn EF, Matzuk MM, Insel TR, Winslow JT (2000) Social amnesia in mice lacking the oxytocin gene. Nat Genet 25(3):284-288

Ferguson JN, Aldag JM, Insel TR, Young LJ (2001) Oxytocin in the medial amygdala is essential for social recognition in the mouse. $\mathrm{J}$ Neurosci 21(20):8278-8285

Ferguson JN, Young LJ, Insel TR (2002) The neuroendocrine basis of social recognition. Front Neuroendocrinol 23(2):200-224

Gimpl G, Fahrenholz F (2001) The oxytocin receptor system: structure, function, and regulation. Physiol Rev 81(2):629-683 
Green L, Fein D, Modahl C, Feinstein C, Waterhouse L, Morris M (2001) Oxytocin and autistic disorder: alterations in peptide forms. Biol Psychiatry 50(8):609-613

Gregory SG, Connelly JJ, Towers AJ, Johnson J, Biscocho D, Markunas CA, Lintas C et al (2009) Genomic and epigenetic evidence for oxytocin receptor deficiency in autism. BMC Med 7:62

Guastella AJ, Mitchell PB, Dadds MR (2008a) Oxytocin increases gaze to the eye region of human faces. Biol Psychiatry 63(1):3-5

Guastella AJ, Mitchell PB, Mathews F (2008b) Oxytocin enhances the encoding of positive social memories in humans. Biol Psychiatry 64(3):256-258

Guastella AJ, Einfeld SL, Gray KM, Rinehart NJ, Tonge BJ, Lambert TJ, Hickie IB (2010) Intranasal oxytocin improves emotion recognition for youth with autism spectrum disorders. Biol Psychiatry 67(7): 692-694

Jones JR, Skinner C, Friez MJ, Schwartz CE, Stevenson RE (2008) Hypothesis: dysregulation of methylation of brain-expressed genes on the X chromosome and autism spectrum disorders. Am J Med Genet A 146A(17):2213-2220

Knobloch HS, Charlet A, Hoffmann LC, Eliava M, Khrulev S, Cetin AH, Osten $\mathrm{P}$ et al (2012) Evoked axonal oxytocin release in the central amygdala attenuates fear response. Neuron 73(3):553-566

Lee HJ, Macbeth AH, Pagani JH, Young WS 3rd (2009) Oxytocin: the great facilitator of life. Prog Neurobiol 88(2):127-151

Miyake K, Hirasawa T, Koide T, Kubota T (2012) Epigenetics in autism and other neurodevelopmental diseases. Adv Exp Med Biol 724:9198

Modahl C, Green L, Fein D, Morris M, Waterhouse L, Feinstein C, Levin H (1998) Plasma oxytocin levels in autistic children. Biol Psychiatry 43(4):270-277

Pan Z, Lu XF, Shao C, Zhang C, Yang J, Ma T, Zhang LC et al (2011) The effects of sevoflurane anesthesia on rat hippocampus: a genomic expression analysis. Brain Res 1381:124-133
Pedersen CA, Caldwell JD, Jirikowski GF, Insel TR (1992) Oxytocin in maternal, sexual, and social behaviors. New York Academy of Sciences, New York

Pinter, O., Z. Beda, Z. Csaba and I. Gerendai (2007). Differences in the onset of puberty in selected inbred mouse strains. Endocrine Abstracts

Ross HE, Young LJ (2009) Oxytocin and the neural mechanisms regulating social cognition and affiliative behavior. Front Neuroendocrinol 30(4):534-547

Satomoto M, Satoh Y, Terui K, Miyao H, Takishima K, Ito M, Imaki J (2009) Neonatal exposure to sevoflurane induces abnormal social behaviors and deficits in fear conditioning in mice. Anesthesiology 110(3):628-637

Schanen NC (2006) Epigenetics of autism spectrum disorders. Hum Mol Genet 15(Spec No 2):R138-R150

Sprung J, Flick RP, Katusic SK, Colligan RC, Barbaresi WJ, Bojanic K, Welch TL et al (2012) Attention-deficit/hyperactivity disorder after early exposure to procedures requiring general anesthesia. Mayo Clin Proc 87(2):120-129

Stoop R (2012) Neuromodulation by oxytocin and vasopressin. Neuron 76(1):142-159

Theodoridou A, Rowe AC, Penton-Voak IS, Rogers PJ (2009) Oxytocin and social perception: oxytocin increases perceived facial trustworthiness and attractiveness. Horm Behav 56(1):128132

Wilder RT, Flick RP, Sprung J, Katusic SK, Barbaresi WJ, Mickelson C, Gleich SJ et al (2009) Early exposure to anesthesia and learning disabilities in a population-based birth cohort. Anesthesiology 110(4):796-804

Winslow JT (2003) Mouse social recognition and preference. Curr Protoc Neurosci Chapter 8: Unit 816

Winslow JT, Insel TR (2004) Neuroendocrine basis of social recognition. Curr Opin Neurobiol 14(2):248-253 